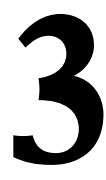

\title{
LA EDUCACIÓN DE LA MUJER ANTES DEL AÑO 1000. ¿ES DHUODA UN CASO ÚNICO?
}

(WOMEN EDUCATION BEFORE THE YEAR 1000. IS DHUODA A UNIQUE CASE?)

Ana Belén Sánchez Prieto

Universidad Complutense de Madrid

\section{RESUMEN}

A pesar de la escasez de fuentes, disponemos de cierta información sobre mujeres, casi todas de familias reales o aristocráticas, que pudieron permitirse poseer manuscritos y que eran capaces de usarlos, e incluso de copiarlos. Algunas sobrepasaron incluso el nivel de consumidoras de literatura para convertirse en productoras, componiendo obras de diversos géneros literarios. Al mismo tiempo los monasterios femeninos sirvieron de escuela para la instrucción de algunas niñas de origen noble que no estaban destinadas a profesar y que volvían al siglo al terminar su educación para casarse, y de esta manera convertirse en el principal vehículo de la educación cristiana y literaria de sus hijos. En definitiva, no se puede decir que la escritura fuese en la Alta Edad Media un privilegio de una casta masculina y clerical, aunque sí se puede afirmar que salvo en casos excepcionales estaba era patrimonio de la aristocracia.

\section{ABSTRACT}

In spite of the scarcity of sources, there is some information about some women, almost all of them members of royal or aristocratic families, that could afford to own manuscripts and were able to use them, and even to copy them. Some of them could reach the highest levels of literacy and became themselves producers of texts in diverse literary genders. At the same time nunneries served as schools for the instruction of girls of noble origin, destined to return 
to the world after finishing their education, and in this way they became a privileged conduct for the Christian and literary education of their children. Definitely literacy was not a privilege of male ecclesiastical hierarchies, although we can ascertain that except in very punctual cases it was confined to the families of the ecclesiastical and lay aristocracy.

\section{INTRODUCCIÓN}

Ningún lector del manualito compuesto por Dhuoda para su hijo Guillermo negará haberse sentido impresionado por la sencillez y la profundidad de las enseñanzas de aquella mujer que, por azares políticos, quedó privada de sus dos hijos.

El tratadito de Dhuoda pertenece al género del enchiridion o speculum, un tipo de manual de moral, según ella misma expone en el prólogo, y en él exhorta a su hijo a mirarse en él, del mismo modo que las mujeres escrutaban sus defectos en los mal pulidos espejos de su época. A tal fin adapta para el joven Guillermo, de 16 años, cuanto ella ha leído en las Escrituras y en los padres, especialmente Agustín de Hipona y Gregorio Magno, así como en Alcuino de York y otros autores del siglo IX (Riché, 1975). Sobre esta urdimbre teje la madre sus enseñanzas para su hijo adolescente con tono simple y familiar, marcado de profunda religiosidad.

De Dhuoda impresiona la sinceridad de su fe cultivada con numerosas lecturas, su amor por la familia, su profundo sentido del deber, su prudencia en los negocios mundanos...; pero sobre todo impresiona que en el siglo IX Dhuoda es mujer y que es esposa y madre, es decir, que es mujer y laica, pues cualquiera de las dos condiciones hubiera bastado para presuponerla iletrada, y de hecho se ha sugerido que Dhuoda se habría limitado a encargar el trabajo a algún clérigo a su servicio (Bessmertny, 1987). Pero el tono emocional de la obra es tan alto y tan intenso, y su enseñanza está muy alejada de las propuestas de los pedagogos eclesiásticos, pues minimiza el poder real y eclesiástico mientras que otorga por el contrario especial relieve a los lazos familiares encarnados en la figura paterna y en el linaje patrilineal (Neel, 1999, McKitterick, 1983), lo cual permite descartar tal hipótesis.

Incontrovertible es que Dhuoda es la única autora de su sexo durante el siglo IX, y que su obra tiene características peculiares que le confieren un puesto aparte en la historia de la literatura. La cuestión esencial es dilucidar cuán de excepcional es Dhuoda y, en consecuencia, si se la puede tomar como espejo en el que mirar a las mujeres de la aristocracia carolingia y occidental en cuestiones tan esenciales como la alfabetización, el grado de educación gráfica y el alcance de su conocimiento de las artes liberales y de sus lecturas. 
No es fácil emitir un juicio al respecto. Por definición, las mujeres han dejado un rastro documental más tenue que los hombres, pero nuestras fuentes no son del todo opacas, y en ocasiones permiten vislumbrar, acaso de soslayo, mujeres en sus actividades cotidianas. Como un cuadro impresionista, los detalles se pierden, pero el conjunto de la imagen se adivina con suficiente nitidez.

\section{ALGUNAS NOTICIAS SOBRE MUJERES CULTIVADAS}

La primera impresión es que Dhuoda no está sola. Ciertas mujeres tuvieron un papel muy activo en los primeros reinos bárbaros surgidos de los despojos del Imperio Romano: Brunilda, Fredegunda, Teodelinda son algunas de ellas.

Nada sabemos del destino de la escuela pública tras la caída del Imperio Romano. Suponemos que desapareció, pero al menos en ciertos círculos sociales tal carencia se cubrió de algún modo, también para las mujeres. Por ejemplo, en Verona, una pequeña de ocho años murió en el 532; su nombre era Plácida, "inlustris puella instructa litteris" (CIL, V, 3897). También en Italia, Estefanía, hermana del senador Fausto, ministro de Teodorico, se aplicó en ejercicios escolásticos (Ennodio, Ep. IX, 18. MGH, AA 7). Y Amalasunta, hija y sucesora de Teodorico, sabía bien latín y griego, y por ello la alabó Casiodoro (Variae, XI, 1 y X, 4; MGH, AA XII).

En España, las hijas de Atanagildo habían sido educadas cuidadosamente (Fortunato, Carm. VI, 5, v. 284, MGH, AA, IV-I, p. 144), y Braulio de Zaragoza, en respuesta a una aristócrata de nombre desconocido que le había solicitado los libros de Tobías y Judith, envió, junto con dichos libros, una carta explicando las figuras retóricas que encontraría allí (Ep. 16). En Inglaterra la hija de Cariberto y reina de Kent, era dama de considerable educación (Gregorio Magno, Ep. XI, 35. MGH, Ep., II, p. 304, 1. 24). Y la abadesa Bugga o Eadburga, de la Isla de Thanet, hija de Centwin de Wessex, envió libros a San Bonifacio, con quien mantuvo correspondencia (Bonifacio, Ep. 15).

En el Continente, Proba, mujer noble de principios del siglo VI, recibió un florilegio de San Agustín del abad Eugipio y correspondió con Fulgencio de Ruspe (Riché, 1976). La parisina Vilihuta, mujer de Dagaulfo, aunque de origen germánico, conocía bien la cultura latina (Fortunato, Carm. IV, 26, v. 15). San Columbano ejerció considerable influencia sobre las mujeres, que se sintieron más seducidas que los hombres por el rigorismo de sus enseñanzas. Gracias a ello, el número de monasterios femeninos aumentó considerablemente en Francia, donde las mujeres pudieron participar así en la 
vida intelectual y espiritual. San Bonifacio contó con la inestimable ayuda de Leoba, quien, según su biógrafo, era muy versada en las Escrituras.

Y todavía más al este, encontramos a la bávara Teodelinda, reina de los lombardos, de quien el rey Sisebuto compuso un adulador retrato (Carta de Sisebuto a Adaloaldo, MGH, Ep. III, p. 673, 11.). Teodelinda mantuvo además correspondencia con Gregorio Magno, que le envió varias de sus obras (Ep. XIV, 12.MGH, Ep. II).

De la Francia carolingia llegan más noticias. Gisela, hermana de Carlomagno, fue calificada por Alcuino de femina verbipotens; y la emperatriz Judit también recibió una esmerada educación (Ward, 1990). En la región de Lyons, dos damas, Constantina y Justina, poseían una selección de tratados cristianos (Lyons, Bibliothèque de la ville, MSS 426 y 604. McKitterick, 1983). Ragydrudis, hija de Artuolfo, tenía una copia de los Synonima de Isidoro (Fulda, Codex Bonifatianus 2. McKitterick, 1983), y los evangelios de Gundohino fueron copiados ex profeso a requerimiento de una dama borgoñona de nombre Fausta (Autun, bibliothèque Municipale, MS 3. McKitterick, 1983). Por último, Leodegundia, hija del rey Ordoño de Asturias, era, según su epitafio, discreta y erudita en las letras y misterios sagrados (Díaz y Díaz, 1979).

\section{EDUCACIÓN}

A pesar del colapso de la escuela pública, la Iglesia necesitaba hombres educados para cubrir los distintos ministerios sacerdotales, de modo que el vacío dejado en la enseñanza hubo de cubrirse mediante la creación de escuelas eclesiásticas.

Es difícil de saber hasta qué punto las muchachas tuvieron acceso a este tipo de educación. En principio, su posición era de desventaja con respecto a los niños, puesto que no sólo no eran aptas para recibir las órdenes sagradas, sino que sobre ellas pesaba la prohibición de hablar y enseñar en la iglesia $(1 C o, 14: 34-35)^{1}$, repetida, entre otros, por Isidoro y los cánones hibernenses: Feminis in ecclesia loqui vel docere non permittitur; sed nec contingere vel conferre ullius virilis muneris aut sacerdotalis officii sortem sibi vindicare (Hibernensis, libro 45, cap. 20.).

Sin embargo, lo cierto es que en la temprana Edad Media la mujer parece haber gozado de una consideración relativamente alta. Cuando Hincmaro de Rheims recomendaba que las niñas no fueran admitidas en las escuelas juntamente con los muchachos (Collectio de Ecclesiis et Capellis, MGH, Fontes XIV, c. 100), está informándonos de que al menos en algunos lugares era práctica común. ¿Acaso no había enseñado San Jerónimo a 
Paula, Eustochium y otras mujeres? ${ }^{2}$. Y el ejemplo de Jerónimo fue conscientemente seguido, entre otros, nada menos que por Benito de Aniano, que en su De Institutione Sanctimonialium utilizó la carta de San Jeónimo a Laeta elogiando la educación de la pequeña Paula para proponerla como modelo de la educación que las niñas deberían recibir en los monasterios ${ }^{3}$. También el gran Pascasio Radberto, en su tratado sobre la Asunción de María, redactado para las monjas de Soissons, emula la mencionada carta de Jerónimo ${ }^{4}$. Finalmente, Gisela y Rodrud, hermana e hija respectivamente de Carlomagno, invocaron la autoridad de Jerónimo cuando solicitaron de Alcuino un comentario sobre el evangelio de San Juan (MGH, Epp. IV).

Así encontramos un considerable número de mujeres que fueron educadas por hombres. He aquí algunas.

Una de ellas es Benedicta, la joven aristócrata que se unió al grupo de Fructuoso de Braga y fue instruida por él en la literatura sagrada (Vita Fructuosi).

En Irlanda las más antiguas vidas de santos nos hablan de vírgenes comenzando su carrera religiosa bajo la tutela de algún varón. Conchubranus relata como Monenna fue consagrada por San Patricio, quien, tras ocuparse directamente de su formación religiosa, la envió a la virgen Athea, que a su vez la confió a un sacerdote para que la enseñara los salmos y "la alimentara con los estudios sagrados”. Además, cuando Monenna retornó a casa de sus padres, estuvo bajo la supervisión del obispo Ibar junto con algunas compañeras (Harrington, 2002). Evidentemente, para Conchubranus el que Monenna fuese educada por hombres no suponía motivo alguno de desasosiego. Poco posterior es la vida de santa Lassair, que se educó junto a Molaisse, un santo varón que enseñaba a niños y niñas conjuntamente. Otro monje, Ciarán, que vivía en el monasterio de San Finnian, se encargó de la educación de una princesa, y le enseñó los salmos (es decir, a leer), pero, según su biógrafo, nunca aquel joven se atrevió a mirar a la princesa, salvo solamente a los pies (Stokes, 1890; Harrington, 2002). Evidentemente, el hagiógrafo ya se sentía incómodo ante la idea de que un monje enseñase directa y personalmente a una mujer.

Sin movernos de las Islas Británicas, según Beda (Historia Eclesiastica IV), el irlandés Aidan instruyó personalmente a Hilda, fundadora en 657 del monasterio dúplice de Whitby. Aldhelmo mantuvo correspondencia con las monjas de Barking y Wimborne y les dedicó sus trabajos sobre la virgini$\mathrm{dad}^{5}$, denominándolas "aluminae scholasticae" y ensalzando su "discipulatus industria”. Bonifacio fue consejero de las monjas de Wimborne, y especialmente de Leoba, Eadburg, Egburg y Eangyth y su hija Bugga (Riché, 1976). $\mathrm{Su}$ biógrafo especifica que su fama como maestro se extendió por todos los 
monasterios de hombres y mujeres, y que a éstas, como no podían acudir continuadamente a sus lecturas, las estimulaba con su vasta sabiduría y su espíritu de amor divino, y ellas se aplicaban diligentemente al estudio de los textos bíblicos, escudriñándolos página a página y meditando sobre sus sagrados y escondidos misterios. Su alumna predilecta, Leoba, le escribió poco después del 732 una carta con unos versos solicitando que corrigiera su estilo desaliñado y rogándole le enviase algún escrito suyo para usarlo como modelo (Bonifacio, Carta n. ${ }^{\circ} 29$ ).

Tanto la superioridad intelectual de los monjes insulares, como su liberalidad para instruir a mujeres, atrajeron indudablemente la atención de muchas de ellas en el Continente. Cuando Gertrudis, hija de Pipino de Landen, fue nombrada abadesa de Nivelles, apeló a sabios de allende los mares para que la ayudasen con sus estudios religiosos (Vita Geretrudis, SRM, II). Igualmente San Columbano influyó decisivamente sobre las fundadoras de numerosos monasterios de la cuenca del Sena, como Faremoutiers (Brie), Juarre, Chelles, Remiremont y el convento de Santa María y San Juan de Laón, que tras un breve periodo se convirtieron en monasterios dúplices bajo el gobierno de una abadesa (McKitterick, 1992). Precisamente desde Luxeuil envió Eustasio a Amatus al cenobio de Ramiremont para que apoyara a su primera abadesa, Mactefledis, e instruyera a sus monjas y monjes en la regla de San Columbano (Vita Amati, Romarici et Adelphii abbatum Habendensiu, c. 8. MGH, SRM, IV). A Faremoutieres, fundación de Burgundofara, fueron enviados Waldeberto, más tarde abad de Luxeuil, y Ghagnoaldo, hermano de la propia Burgundofara, para enseñar la Regla a las hermanas (Vita Columbani, II, c. 7. MGH, SRM IV). Bonifacio supervisó a las monjas de Kitzingen, Ochsenfurt y Tauberbischofsheim (McKitterick, 1986; 1992). Finalmente, en el Liber confraternitatis de Remiremont aparece con las hermanas de Faremoutiers un magister, el monje Theudenus, que junto al también monje Irmindus tenía probablemente la misión de enseñar a las monjas y las novicias (McKitterick, 1994b).

La información disponible sobre las muchachas que decidían permanecer en el siglo es más escasa, pero diversos indicios permiten adivinar que en algunos casos su educación era cuidadosamente planificada, y que aprendían a leer y a escribir con preceptores masculinos, pues las casas nobles eran uno de los lugares tradicionales para que los jóvenes de ambos sexos aprendieran las habilidades necesarias para su vida adulta. A finales del siglo VII, un período en el que la cultura se hallaba en franca decadencia, informa Venancio Fortunato de que unas jovencitas de Aquitania eran tan habilidosas con la pluma como con el huso (Carmina, t. IV).

Sin duda, como lugar privilegiado de educación destacan las cortes reales, y sabemos que tanto en la Toledo ${ }^{6}$ como después en la de Mercia y en la 
del rey Alfredo el Grande se acogía tanto a hijos como a hijas de magnates (Orme, 2006). En Aquisgrán, a las lecciones de Alcuino, acudían, junto con Carlomagno y sus hijos, su mujer, la reina Liutgarda, su hermana Gisela, sus hijas Rotrud y Gisela, y su prima Gundrada (West, 1892).

Finalmente, para ilustrar este período, incluimos a continuación una divertida anécdota narrada mordazmente por Liutprando de Cremona, a propósito de Willa, una princesa toscana, esposa de Berenguer II:

Tenía ella por su capellán a un curilla llamado Domingo, bajo de estatura, renegrido, rústico, basto, de malos modales, paleto, maleducado, peludo, estúpido, agresivo, insensato, testarudo, desmedido, a cuyo magisterio había encomendado Willa a sus dos hijas, a saber Gisla y Girberga, para que las intoxicara con el conocimiento de las letras.

Empero, no tenemos noticias sobre muchachas educadas por preceptores fuera de los círculos aristocráticos, salvo la vaga noticia de los estatutos del obispo Riculfo de Soissons, que parecen sugerir que al menos en ciertas parroquias se impartía alguna de educación a las niñas (Statuta del obispo Riculfo de Soissons, c. 16. PL 131, col. 21).

\section{ENSEÑANZA IMPARTIDA POR MUJERES}

De todos modos, tenemos motivos para suponer que la mayoría de las muchachas recibían su educación de otras mujeres ${ }^{7}$, lo que implica que muchas de ellas alcanzaban un nivel cultural suficiente como para enseñar.

Como es habitual, la mayoría de las fuentes hacen referencia a instituciones religiosas, no sólo porque allí se volvía necesaria la educación de las novicias, sino sobre todo porque la oblación de niños se convirtió en una práctica muy común ${ }^{8}$. La consecuencia fue la necesidad de ocupare de la educación de estos pequeños (De Jong, 1986), con los que al menos en ocasiones serían admitidos niños de la localidad no destinados a profesar'.

Por ejemplo, Beda, relata que Earcongorta, hija del rey Eaconbert de Kent, profesó en un monasterio de Brie, "porque aún había muy pocos monasterios en territorio inglés, y la mayoría de los que querían profesar en un convento marchaban de Gran Bretaña al reino franco o a la Galia con tal propósito. Niñas de familia noble eran enviadas allí también para ser educadas o prometidas a su celestial esposo, especialmente en las casas de Brie, Cheles y Andelys..." (HE III). 
Aparte de aprender a coser y bordar, la educación de las niñas no debía ser muy distinta de la que se impartía a los niños. Según la prescripción de Cesario de Arlés, tenían que aprender el psalterio, y la regla de Waldeberto de Luxeuil ${ }^{10}$ describe el ambiente donde se criaban las niñas:

Hemos enseñado en muchos escritos con cuánto cuidado y disciplina deben ser criadas las niñas. En efecto, deben ser criadas con todo afecto y piedad, pero también con disciplina, para que a esta tierna edad no queden manchadas por vicio de pereza o lascivia, aunque sea poco, de modo que no puedan ser corregidas más adelante. Que se tenga con ellas tanto cuidado que nunca les esté permitido andar por aquí o allá sin una monja adulta, y que siempre manteniéndose en la disciplina e inmersas en la doctrina del temor de Dios y del amor, se las instruya en el culto de la religión. Que frecuenten la lectura para que aprendan en la edad infantil lo que les aprovechará en la adulta. En el refectorio tendrán para ellas una mesa colocada junto a la de las adultas, pero dos o más monjas adultas de cuya piedad no quepa duda, se sentarán con ellas, de modo que, antepuesto el temor, sean criadas en el respeto de las mayores.

Las vidas de santos recogen también algunas escenas educativas. Por ejemplo, la Vita I de Santa Brígida menciona a una discípula suya (Vita I de Santa Brígida, caps. 47, 75 y 126). Y la Vita Liutbergae informa de que esta santa enseñó canto a las niñas (Vita Sanctae Liutbirgae, 35. MGH SS IV).

Leoba fue entregada a la madre Tetta para que la instruyera en las ciencias sagradas (Rodolfo de Fulda, Vita Leobae, Talbot, 1954), y fue criada con sumo cuidado por la abadesa y las otras monjas, "sin mostrar otro interés que adquirir santa sabiduría, y así, lejos de perder el tiempo con historias infantiles, se aplicó a la lectura y a escuchar la palabra de Dios, y todo lo que leía o le era leído lo retenía en su memoria, y todo lo que aprendía lo llevaba a la práctica, y así se ejercitó en la moderación en la comida y en la bebida y oraba continuamente, o trabajaba manualmente, porque había aprendido que el que no trabaje que no coma. Pero sobre todo pasaba el tiempo leyendo y escuchando las Sagradas escrituras, e imitaba las mejores cualidades de cada una de las monjas". Por otras fuentes sabemos que aprendió a componer poesía de su maestra Eadburg (Bonifacio, Ep. 29), y que después enseñó, siendo ya abadesa de Bischofsheim (753-54), y aceptó educar temporalmente a una muchacha que le encomendaron el sacerdote Torhtaht y San Bonifacio (Bonifacio, Ep. 96).

El proceso educativo debía comenzar lo antes posible. Por ejemplo, la joven Rusticila podía recordar los versículos que su niñera le recitaba cuan- 
do la tenía en brazos (Florentius, Vita Rusticulae, 6, MGH, SRM, IV). Y en el monasterio de Leoba se practicaba la hipnopedia (McKitterick, 1986-90). La instrucción era básicamente religiosa, e incluía la lectura y la escritura, pero muchos textos hagiográficos destacan sobre todo las habilidades relacionadas con la artesanía textil (Wemple, 1981).

Algunos textos permiten suponer que en ciertos monasterios femeninos se admitían niñas no destinadas a profesar. Es difícil decir si la muchacha encomendada a Leoba por Bonifacio y Torhthat tenía la intención de volver al siglo, pero el hecho de que el encargo fuera temporal parece indicarlo.

En Alemania, al menos entre los siglos IX y XI, muchos monasterios femeninos admitían a muchachas nobles que tras su educación regresaban al mundo en lugar de tomar los hábitos. Por ejemplo, el duque Liudolfo envió a sus cinco hijas a la abadía de Gandersheim ${ }^{11}$ (McKitterick, 1994a); tres de ellas permanecieron allí, pero dos se casaron (Lett, 1999). Y la reina Matilde, esposa de Enrique I de Alemania, había estudiado en el monasterio de Herford (Vita Mathildis Reginae Antiquior, cap. 1, SS rerum Germanicarum). Otros monasterios como Meschede, Vreden, Freckenhors, Essen y Geresheim, todos fundaciones del siglo IX, acogían con toda probabilidad jóvenes para su educación (Faust, 1984).

Finalmente, en el caso de Inglaterra tenemos pruebas de que Edith, hija del conde Godwine y mujer de Eduardo el Confesor, se había educado entre 1030-1040 con las monjas de Wilton Abbey, y tenía reputación de ser entendida en música, gramática y lenguas, saberes que indudablemente aprendió en la abadía (Stafford, 1997; Orme, 2002).

Sin embargo, carecemos por completo de noticias sobre la educación de las niñas de clase campesina. Tomás de Cantimpré, en el siglo XIII, relata una historia encantadora (Bonum universale de apibus, I, 23):

Una pequeña campesina suplicó a su padre que le comprara un salterio para poder aprender a leer. “¿Pero cómo”, contestó él, "podría comprarte yo un salterio, si apenas puedo ganar lo suficiente para comprarte pan cada día?" La niña quedó contrariada, pero después vio en un sueño aparecer a la bienaventurada Virgen, sosteniendo dos salterios en las manos. Animada por esta visión se dirigió de nuevo a su padre. "Hija mía", le dijo el padre, "ve cada domingo a visitar a la maestra de la parroquia; pídele que te de unas pocas lecciones y trata de hacerlo lo mejor posible para ganar uno de los dos salterios que has visto en las manos de la Virgen". La niña obedeció, y percatándose de su celo, sus compañeros reunieron el dinero suficiente para comprarle el libro que ella había deseado tanto. 
Desgraciadamente nada hay que permita creer que pudo suceder algo parecido antes del año 1000.

De lo que sí hay noticias es de que las monjas educaban a veces también a niños: Beda nos informa de que en el monasterio de Barking vivía un niñito de tres años llamado Aesica, que por ser tan pequeño era criado y educado en las celdas de estas vírgenes (HE IV, 8.). En Irlanda, Monenna y sus compañeras lograron la conversión de un rey (Harrington, 2002), y las vidas de santos desde el siglo $\mathrm{X}$ contienen numerosos ejemplos de santos educados en su infancia por vírgenes, pero que al alcanzar la pubertad fueron enviados a un sacerdote (Harrington, 2002) ${ }^{12}$. En Northumbria, Hilda, sobrina-nieta del rey Edwin, fundó en el 657 el monasterio dúplice de Whitby, donde enseñó a monjes e incluso a laicos y futuros obispos (Beda, HE IV). Lull fue educado en el monasterio dúplice en Inkberrow por Cyneburh, que también enseñó a Denehardo y Burchard, y por Fufanna en otro monasterio sin identificar, también en Inglaterra (Bonifacio, Ep. 49) (Sims-Williams, 1976). Asimismo en Inglaterra, en el convento de Wenlock, se formó cierto visionario varón (Bonifacio, Ep. ed. RAU, n. ${ }^{\circ} 10$ ), y Guthlac fue educado en Repton (Vita Sancti Guthlaci auctore Felice, cap. 42) (McKitterick, 1994b, p. 38). En la Francia carolingia la ermitaña Wiborada enseñó a Oudalricus, monje de St Gall (Vita Sanctae Wiboradae, c. 39, MGH SS IV).

Pero los casos más impresionantes lo encontramos en el siglo X: con Hrostswitha de Gandersheim, que además de escribir se dedicó a la docencia, y sobre todo Hedwig de Babiera, sobrina de Otón I, que había estudiado griego como preparación para su matrimonio con Romano, hijo del Emperador de Bizancio Constantino Porphyrogeneta; aquel matrimonio nunca tuvo lugar, pero Hedwig aprovechó su talento para enseñar griego a los monjes de San Gall (Holzmann, 1961; Contreni, 1990).

Ahora bien, donde la labor didáctica y educativa de la mujer altomedieval encontraba su lugar natural era dentro de la propia familia, en la que sin duda se encargaba del cuidado de sus hijos, y de manera muy especial de la transmisión de la fe (Delumeau, 1992). De hecho, Dhuoda compuso su Liber Manualis para Guillermo simplemente porque Guillermo estaba en la corte y no podía recibir directamente las enseñanzas de su madre (Liber Manualis, I.7). Si Guillermo y el pequeño Bernardo hubieran permanecido en la casa paterna, Dhuoda no lo hubiera escrito, según ella misma declara en el prólogo. Su tragedia personal es fortuna para nosotros, porque nos permite vislumbrar las enseñanzas que una madre de la aristocracia carolingia impartía a sus hijos adolescentes.

Pero tampoco aquí Dhuoda es un caso aislado. Las escasas fuentes también nos permiten entrever la labor de madres instruidas en beneficio de 
sus hijos. En el tránsito del siglo VI al VII, Desiderio de Cahors, nacido en Albí en el 590, y sus hermanos recibieron una completísima educación literaria de su padre y su madre (Vita Sancti Desiderii, MGH, SRM, IV), de quien se conservan tres cartas en un latín bastante correcto (Riché, 1976). Brunhilda, princesa visigoda y mujer de Sigeberto, asumió personalmente la educación de su hijo, con tan gran diligencia que el mismísimo Gregorio Magno la felicitó (Ep. VI, 5, MGH, Ep. I) ${ }^{13}$. Hugo, medio-hermano de Carlos Martel y futuro abad de San Wandrille y arzobispo de Rouen, fue educado por su abuela Ansfledis (Gesta Fontanellensis coenobii IV.1), que le inició en las letras y la vida religiosa y le enseñó las habilidades necesarias para progresar en su carrera política y eclesiástica. Finalmente, también la madre del rey Alfredo el Grande, a pesar de las quejas de éste, no dejó de preocuparse por inculcar en sus hijos el amor por la cultura, según la conocidísima anécdota relatada por Asser (Vida de Alfredo el Grande, 23):

Cierto día, su madre les enseñó a él y a sus hermanos cierto libro de poesía en inglés que mantenía entre sus manos y dijo: "Al que de vosotros se aprenda más rápido este libro se lo regalaré". Estimulado por sus palabras, e incluso aún por inspiración divina y atraído por la belleza de la primera letra del libro, adelantándose a sus hermanos que eran mayores que él en años pero no en afecto, se dirigió a su madre diciendo: “¿De verdad darás el libro a aquel de nosotros que lo pueda comprender más rápidamente y recitártelo?” Y su madre, sonriendo regocijada, se lo aseguró y dijo: "Desde luego que se lo daré". Entonces, inmediatamente [el pequeño Alfredo] tomó el libro de manos de su madre, se fue para su tutor y lo leyó. Cuando lo hubo leído lo trajo de nuevo a su madre y lo recitó.

\section{LECTURAS Y BIBLIOTECAS}

Por otra parte, no es excepcional encontrar en las fuentes referencias a mujeres lectoras y poseedoras de libros, y aún de bibliotecas. La propia Dhuoda se declara lectora asidua ${ }^{14}$, y por el tono profundamente personal de su escrito se puede suponer que, además de las obras de los padres latinos, conocía escritos de Alcuino y otros autores del siglo IX, como Ambrosio Autperto, Jonás de Orléans, Paulino de Aquilea, Rabano Mauro y Lupo de Ferrières, además de las de Isidoro de Sevilla, Venancio Fortunato y Gregorio de Tours (Riché, 1975). ¿Acaso era excepcional en Dhuoda su afición a la lectura?

Aparentemente no existe ninguna razón para pensar que en los monasterios femeninos no se diera la misma importancia a la lectura que en los masculinos. Por ejemplo, en la regla de Cesario de Arlés la lectura es una ac- 
tividad encarecidamente recomendada, no sólo individualmente durante dos horas al día (Statuta sanctarum virginum, 19) ${ }^{15}$, sino también en común, durante la comida o mientras se realizaba algún tipo de trabajo manual (Statuta sanctarum virginum, 18). Y Leandro de Sevilla, en la regla compuesta para su hermana Florentina, determina que las monjas oren y lean, intentando extraer el sentido espiritual, aunque, eso sí, evitando las "lecturas carnales" del Antiguo Testamento (Regula ad virgines, 6 y 7. PL, 72). También para Florentina y sus monjas compuso Isidoro su De fide catholica contra Judeos, para que pudieran profundizar en las lecturas del Antiguo Testamento (PL 83, 449). Las reglas de Waldeberto (caps. 9, 12, 24. PL 88) y Donato de Besançon (Caps. 6, 8, 20, 33, 62. PL 87) siguen pautas similares.

De la vida de Leoba, escrita durante el siglo IX por el monje Rodolfo de Fulda se deduce la misma conclusión: que las monjas leían con asiduidad, e incluso se servían de sus conocimientos de gramática para profundizar en el sentido de las Sagradas Escrituras. Y Gisela, abadesa de Chelles hacia el año 800, femina verbipotens al decir de Alcuino, era también consumada lectora, siempre ávida de nuevos conocimientos, pues en una carta Alcuino se lamenta de no poder estar a su altura: “iSi sólo — dice— mi facultas scribendi igualara tu voluntas legendi!” (poema XII, línea 6, MGH, Poet., p. 237; y ep. 213, MGH, ep. 4,).

También se conservan devocionarios que parecen destinados a viudas más que a monjas. Las variantes de copia parecen sugerir que se utilizaban privadamente (Harrington, 2002, p. 199) ${ }^{16}$. Y el "Libro de Nunnaminster" un oracional privado escrito en Southumbria hacia el año 800, perteneció a la reina Ealhswith ${ }^{17}$. Todo indica que los devocionarios ricamente decorados debieron de ser frecuentes entre las mujeres nobles (Lapidge, 1996).

Como caso curioso y probablemente excepcional citaremos el del monasterio de la Santa Cruz en Poitiers. En él las monjas, con su abadesa Radegunda a la cabeza, seguían una versión muy relajada de la regla de Cesario de Arlés, estándoles permitido incluso recibir hombres dentro del claustro. Entre otros, visitó a las monjas el poeta Fortunato, y al parecer las lecturas profanas eran algo habitual, y la propia abadesa Radegunda escribió versos (Gregorio de Tours, HF, IX, 40; Fortunato, App. carminum, Carm. 21, v. 1) ${ }^{18}$.

Otra curiosidad: en las listas de préstamo de las bibliotecas de Colonia y Weissenburg figuran los nombres de varias mujeres (McKitterick, 1989a).

Por tanto, si las monjas leían al igual que sus hermanos varones, debían poseer también bibliotecas más o menos amplias. Esto está atestiguado en la regla de Cesario de Arlés, que menciona a una monja a cargo de los libros. Y sin duda el monasterio de la abadesa Eadburga contaba una bi- 
blioteca bien nutrida, pues de otro modo no hubiera podido enviar libros a Alemania para san Bonifacio (Bonifacio, ep. 30).

También debió de poseer una biblioteca notable el monasterio de San Salvador de Brescia (McKitterick, 1994b), que tenía importantes vinculaciones con la casa real. En Sajonia, de Essen nos ha llegado una pequeña lista de 18 libros no litúrgicos que poseyó el monasterio y que formaron parte de su biblioteca junto con otros que no figuran en ella, pero que han llegado hasta nosotros (McKitterick, 1994b; Karpp, 1988) ${ }^{19}$. También contamos con listas de libros procedentes de Kochel, Lamspringe, Altmünster in Mainz, Meschede, Quedlinburg, Andlau y Zürich (McKitterick, 1994b). No hay razón para suponer que en otros grandes monasterios femeninos del imperio otónida, como Niedermünster, Kitzinger, Gandersheim, Frenckenhors o Herford no hubiese bibliotecas semejantes. Ciertamente, al menos en Gandersheim hubo un manuscrito de Terencio, copiado por las monjas Adelheit, Hetwich y Mathilt en el siglo X (Villa, 1984; McKitterick, 1994b), lo que indica que en esta biblioteca monástica no sólo se conservaban libros de naturaleza religiosa.

También poseemos indicios de que algunas grandes damas poseyeron bibliotecas personales. Ya hemos mencionado las lecturas de Dhuoda. Las tres hijas del conde Eberhard de Friuli heredaron de su padre una biblioteca relativamente extensa, que incluía una copia de las leyes de los lombardos (Riché, 1963).

Un caso singular es el de la condesa gallega Mummadona Díaz, hermana de leche de Ramiro II de León, que en el año 859 fundó el monasterio de Guimarâes, al que dotó con una - para la época- rica biblioteca, que tuvo que ser de su propiedad anteriormente. Aparte de los consabidos y necesarios libros litúrgicos, Mummadona legó una colección sustancial de reglas monásticas, obras de san Isidoro, san Ildefonso y san Gregorio Magno, una Vita Martini y una Historia Eclesiástica (acaso la de Rufino en traducción de Eusebio), un Ephrem Syrus y un Troyano (probablemente los Dictys Cretensis) ${ }^{20}$ (Matoso, 1981). ¿Los habría leído la condesa previamente?

\section{MUJERES Y PATRONAZGO}

Y las mujeres no sólo coleccionaron, sino también encargaron y financiaron la copia de libros ${ }^{21}$.

Comenzaremos por el llamado códice de Ragydrudis, hija de Arthuolfo, que contiene los Sinónimos de san Isidoro ${ }^{22}$, en minúscula luxeuiense de finales del siglo VII o principios del VIII. No sabemos con exactitud quién 
era esta dama, (McKitterick, 1989a), pero en el folio 2v una inscripción informa expresamente de que in honore domini nostri Ihesu Christi ego, Ratyndrudis, ordinavi librum istum, o sea que muy probablemente fue un regalo que hizo al monasterio y que no fue compuesto para su uso personal. Otro testimonio relacionado con éste es el llamado códice de Gundohinus ${ }^{23}$; un copista laico lo completó en el 754 ó 757 por encargo de Fausta y del monje Fulculfo, del monasterio de Santa María y San Juan, acaso de Laón. Madalberta de Meaux, a finales del mismo siglo, encargó una copia del De Trinitate de san Agustín ${ }^{24}$, y Adeldrudis comisionó un códice ${ }^{25}$ para el obispo Arnulfo de Metz (McKitterick, 1989a). Godgifu (o Godiva), mujer del conde Leofric de Mercia, en la primera mitad del siglo XI, según Orderico Vitalis, "envió orfebres y les dio gran cantidad de oro y plata para convertirlos en cubiertas para evangeliarios, cruces e imágenes de santos". Recordaremos aquí así mismo el caso de la gallega Mummadona Díaz, que donó numerosos libros al monasterio de Guimarâes, incluyendo algunos realmente infrecuentes en su época.

Pero las mujeres de esta época no sólo encargaron copias de obras anteriores. Algunas de ellas también impulsaron la redacción de nuevas obras, contribuyendo de este modo al progreso del conocimiento ${ }^{26}$. Aparte de los archiconocidos encargos de Gisela y Rodturd a Alcuino de York, Prudencio de Troyes (muerto en el 861) escribió una pequeña introducción a la Biblia para una dama de nombre desconocido (PL 115, cols. 1449-56). Gerberga, mujer de Luis IV y hermana de Otón I, encargó de Adso de Moutier-en-Der una obra titulada De ortu et tempore antichristi (PL 101, cols. 1291-1297 y CCCM, 45).

Las creaciones en lengua vulgar también tuvieron mucho que ver con las mujeres. Beda el Venerable relata como el poeta-pastor Caedmon recibió la protección de la abadesa de Whitby, que lo instruyó en las Sagradas Escrituras, para que pudiera cantarlas poéticamente en anglo-sajón (HE, IV, 22).

Al parecer la historia fue una materia que interesó grandemente a las mujeres. La reina Teodelinda, bávara de nacimiento y lombarda por matrimonio, encargó a su consejero, el monje Segundo de Trento, escribir la historia de su pueblo (Paulo Diácono, Historia Langobardorum, IV, 40. MGH, Scriptores rerum Langobardicarum et Italicarum saec. VI-IX). Freculfo de Lisieux dedicó su Gesta imperatorum et regum a la emperatriz Judith, concebida para ayudar a la educación de su hijo (Paulo Diácono, Historia romana, MGH, SRL, p. 13) (Goffart, 1988); Aethelflaed aparece en el llamado Registro de Mercia (Nelson, 1996a,) y su madre Eahlswith, la mujer de Alfredo el Grande, se implicó personalmente en la composición de la Crónica Anglo-Sajona (Parkes, 1983), la abadesa Gerberga de Gandersheim encargó las Gesta de su pariente Otón I (Hrosvitha, Gesta Ottonis, ed. P. Winterfeld, 
MGH, SRG, Berlin, 1902, prefacio, p. 201). La duquesa Gunna patrocinó el De moribus et actis primorum Normanniae ducum de Dudo de San Quintín (Searle, 1984); y la reina Mathilde de Inglaterra las genealogías y trabajos históricos de Guillermo de Malmesbury (Nelson, 1996a). El Encomium Emmae reginae lo mandó componer ella misma durante el reinado de su hijo Harthacnut (1040-1042) con el propósito de exaltar la dinastía danesa de Inglaterra (ed. A. Campbell, The Camden Third Series, 72, London, 1949). En este apartado podría incluirse también a otra Gerberga, hermana de Otón I y reina de los francos occidentales, pues la mencionada obra de Adso de Moutier-en-Der, el De ortu et tempore Antichristi, es mitad historia mitad profecía. Ninguna de estas mujeres ignoraba la importancia que el patrocinio de obras históricas podía tener como instrumento de propaganda para una casa reinante.

En el ámbito de un subgénero de la historia, muchas vidas de santos también fueron escritas para mujeres o encargadas por ellas. Por ejemplo, Rodolfo de Fulda escribió su vida de Santa Leoba para Hadamout, virgen de Cristo, y Eigil de Fulda compuso la de San Sturm para Angildruth. Como último ejemplo citaremos a Hucbaldo, autor de una vida de Santa Gertrudis, a petición y tras recibir la documentación necesaria de las monjas de Marchiennes (PL 132, 829) (Laistner, 1957). Tampoco en estos casos la intención publicitaria debía de estar totalmente ausente.

\section{CORRESPONDENCIA DE MUJERES}

Otra manifestación del interés que tenían muchas mujeres por participar en los distintos movimientos políticos y culturales de su época proviene de la correspondencia que mantenían con otras personalidades de importancia. Los Monumenta Germaniae Historica contienen misivas de no menos de 55 mujeres que envían o reciben cartas, la mayoría durante los siglos VIII y IX.

Una consideración previa se hace necesaria: durante esta época las cartas en su inmensa mayoría se conservan solamente en colecciones compiladas a posteriori con finalidad didáctica, ya que servían como modelos literarios, o bien eran escogidas por la importancia de su contenido. Hay que suponer por tanto que la inmensa mayoría de las cartas escritas durante la Edad Media se ha perdido. Su conservación depende de la existencia de un compilador que las considerara de suficiente interés como para iniciar su transmisión como obra literaria.

Si las cartas las escribían personalmente o recurrían a un secretario importa sólo hasta cierto punto, puesto que incluso en este último caso la 
iniciativa habría correspondido a las mujeres que decidieron establecer el contacto recurriendo a medios escritos (McKitterick, 1994b).

\section{AUTORAS}

El epistolar no es sin embargo el único género literario practicado por las mujeres altomedievales; la historia, la hagiografía, los relatos de viajes y el speculum o tratado moral fueron también objeto del interés femenino.

De las obras conservadas de los siglos anteriores al año 1000, tan sólo un puñado de ellas salieron de las plumas de mujeres conocidas. Aparte de Dhuoda, no se puede olvidar a Egeria, Eucheria, Radegunda, Baudonivia, Hugeburc y sobre todo Hrostivta de Gandersheim, todas sobradamente conocidas. El Hodoeporicon de Hugeburc es muy representativo de la actitud de muchas mujeres a la hora de firmar sus creaciones, pues se la tuvo por obra anónima durante largo tiempo, hasta que Bernhard Bischoff descifró el criptograma de un manuscrito antiguo (1931).

Pero naturalmente hay muchas otras que permanecen en el anonimato, o cuyas obras simplemente se han perdido. Un ejemplo de lo primero lo constituyen las vitae Balthidis y Geretudis, del siglo VII (MGH, SS rer. merov. II). En cuanto a lo segundo, sabemos que la reina Mathilda, en su lecho de muerte, puso en manos de su nieta, la abadesa de Quedlinburg, un computarium en el que "había escrito los nombres de los muertos" (Vita Mathildis reginae antiquior, cap. 10. MGH, SS 10).

Y aún disponemos de más noticias. Por ejemplo, una capitular carolingia prohibía que las monjas escribieran o enviasen "winileodas", género en el que, al parecer, eran muy habilidosas (MGH, Cap. I, n 23, c. 19).

Finalmente, no es improbable que algunas de las múltiples obras de autor anónimo conservadas fueran escritas por mujeres. La cuestión estriba en determinar qué características distintivas debería tener la obra de una mujer, teniendo en cuenta que las niñas recibían una educación sustancialmente idéntica a la de los niños. P. Dronke ha visto en las mujeres una cierta "cualidad de inmediatez", procedente "de una fuerza interior que las impele y apremia a escribir" (1984, p. x), pero este criterio es excesivamente subjetivo y por tanto poco útil. Janet Nelson (1990b) ofrece otros criterios de mayor operatividad. Por ejemplo, es muy plausible que una mujer que escriba historia tienda a prestar atención a las protagonistas femeninas, y eso, en efecto, sucede en la obra de Hrostvitha, así como a resaltar los lazos de parentesco y afecto dentro de la familia. Finalmente, R. McKitterick 
(1994b) añade el principio de procedencia. Por ejemplo, ¿no es más lógico postular que el autor de una biografía de la fundadora de un convento de monjas o canonesas sea una mujer - una de ellas, de hecho- que no un hombre? ${ }^{27}$.

Aplicando estos y otros criterios, para el siglo IX, se ha postulado una autoría femenina para el Liber Historia Francorum (Gerberding, 1987; Nelson, 1990b), los Annales Mettenses Priores (Hoffmann, 1958, p. 53-61; Haselbach, 1970, p. 23-5, 284-90), los Annales Quedlinburgenses (Sonnleitner, 1988, 1987), así como las vitae de las fundadoras de monasterios femeninos. Este es el caso de la Vita Balthildis (MGH SRM II), escrita poco después de su muerte hacia el 680 por una monja de Chelles y reelaborada por otra en el siglo IX; el de la Vita Geretrudis y su Continuatio, redactada hacia el 783 (De Virtutibus y Virtutum sanctae Geretrudis continuatio, MGH SRM II); y las vitae Glodesindis (AA SS, 25 de julio), Aldegundis (MGH SRM VI), Eustadiolae (AA SS 8 de junio), las de Herlindis y Reglindis de Aldenijk (AA SS 22 de marzo), etc ${ }^{28}$, así como la Vita sanctae Bertilae (MGH SRM 4), de finales del siglo VIII o principios del IX, escrita acaso por una monja de Chelles o de Jouarre. También parece plausible una autoría femenina para las Vitae Amati, Romarici et Adelphii (MGH SRM IV), fundadores de Remiremont, compuesta más o menos a la vez que su Liber Memorialis, al principio del reinado de Luidovico Pío. Del período siguiente proceden las vidas de Liutberga (MGH SS IV), Odila (MGH SRM VI) y las dos de la reina Matilda (MGH SS X y MGH SS IV).

Una última cuestión a tener en cuenta es hasta qué punto una mujer es, en cuanto autora, consciente de su feminidad y hasta qué punto puede considerarla como un obstáculo para el éxito de cierto tipo de escritos (McKitterick, 1994b), como podría desprenderse, por ejemplo, del prefacio de Huneberc de Heidenheim a su Hodoeporicon, en el que casi viene a disculparse, como si la propia autora tuviera conciencia de que escribir fuera tarea de hombres. Así, se presenta como "una frágil mujer ... cuando hay tantos santos sacerdotes capaces de hacerlo mejor". A la "fragilidad" de su sexo alude también en Dhuoda, aunque vence la determinación de instruir a Guillermo, a pesar de la distancia. Y, finalmente, también Hrostvitha declara componer su obra casi en secreto y "a pesar de que la composición métrica parece dificultosa y hasta ardua para las mujeres, frágiles como somos".

Pero no nos dejemos engañar. De frágil en estas mujeres hay bien poco. La fórmula de humildad y el aparente miedo a las críticas en los prefacios de las obras es un topos muy común, también entre los autores masculinos. Hrostvitha puede que tenga miedo a las críticas, pero a la vez se muestra resuelta y segura de sí misma (Nelson, 1996a; 1996b); Huneberc se siente más que autorizada para escribir por ser pariente de sus biografiados, 
y en el caso de Dhuoda es precisamente la "fragilidad" de su sexo lo que le otorga la autoridad ante el adolescente Guillermo y le permite comunicarse con él en la manera en que lo hace. Al escribir, ninguna de estas mujeres se siente fuera de lugar. No hay nada específico de género en el hecho de escribir.

\section{CONCLUSIONES}

En conclusión, a pesar de la escasez y el laconismo de las fuentes, tenemos información sobre un buen número de mujeres que poseían, utilizaban y copiaban manuscritos, e incluso sobre algunas que, no contentas con consumir literatura, también la produjeron, y cultivaron diversos géneros literarios.

Los monasterios femeninos sirvieron de escuelas para la educación de algunas mujeres de la nobleza y fueron la sede de escriptorios con una función determinada dentro de la organización eclesiástica de su época, contribuyendo así a la vida de la Iglesia, a pesar de que las mujeres tenían vedado el acceso a las órdenes sagradas. A su vez, las damas laicas, formadas a veces en esos mismos monasterios, se constituían en las principales trasmisoras de la educación en el seno de sus familias; también ellas poseían y leían libros e iniciaban a sus hijos e hijas en la lectura y en la fe cristiana, como había iniciado Dhuoda a Guillermo.

Definitivamente, la escritura no fue, durante la Alta Edad Media, un privilegio de una élite masculina y clerical, aunque probablemente sí que tuvieron sobre todo acceso a ella los integrantes de las clases superiores de la sociedad. Además, a partir del año 900 todos pudieron comenzar a servirse de las nuevas posibilidades de expresión que ofrecían las lenguas vernáculas. 


\section{NOTAS}

1. No obstante, véase también Fi, 4: 2-3.

2. La imagen se encuentra en el frontispicio de la Biblia del Conde Vivian, regalada a Carlos el Calvo, probablemente en el 846 (Paris, BN, MS lat. 1, fol. 3v). Ha sido reproducida en color por F. Mütherich-Gaehede, 1977, 76, lám. 21, y comentada por Nelson 1996c, 225.

3. Concilium Aquisgranense a. 816, MGH, Con I, pp. 454-4.

4. De Assumptione Sancta Mariae Virginis, CCCM 56c, 109-62.

5. Aquellas monjas debían pues de saber leer algo más que los salmos, si San Aldhelmo las creía capaces de entender sus sutilezas y su estilo "hermenéutico". MGH, AA, XV, 120, 1, 4.

6. Cuando Fortunato describió la partida de Galswintha hacia la Galia, mencionó también a las muchachas que acompañaban a la princesa. Carm. VI, 5, MGH, AA, IV-1, 136. Aunque casi con seguridad es una leyenda, la de don Rodrigo y la Cava es una prueba de que la presencia de muchachas en la corte visigoda no era algo extraordinario.

7. Periódicamente se produjeron intentos de eliminar cualquier presencia masculina de los monasterios de monjas, por ejemplo, en una capitular de 802 .

8. Según relata Beda (HE III.24), en 654 Oswiu de Northumbria entregó a su hija Aelfflaed, de un año, en agradecimiento por su victoria en una batalla. Sin embargo, hasta poco antes de esa fecha, si una muchacha quería ingresar en un monasterio (o sus padres querían que lo hiciera), debía marchar a Francia, probablemente a Faremoutiers-en-Brie y Andelys-sur-Seine (HE III.8).

9. Cesario de Arlés prohibió expresamente. Regula ad Virgines, c. 7.

10. PL 88, col. 1054ss, donde aparece como de autor desconocido. Cap. 24 en 107. Esta información puede ser complementada con una frase de la gramática de Aelfric de Eynsham: "Esta monja es constante en enseñar a las niñas".

11. Cuya colección de manuscritos sugiere un alto nivel cultural.

12. Brendan, por ejemplo, fue criado por Ita y después enviado a Erc.

13. "Excellentiae vestrae praedicandam ac Deo placitam bonitatem et gubernacular regni testantur et educatio filii manifestat".

14. II.1; III.1; IX.1, por ejemplo.

15. Pero el mismo Cesáreo prescribe para los varones tres horas en lugar de las dos de las mujeres.

16. Los manuscritos referidos son Bodleian Rawlinson MS B. 512; Bruselas, MS 4190; BM Additional MS 30 y BM MS Egerton 92.

17. London, BL, Harley 2965, CLA II, no. 199. Estudiado en Alexander 1978.

18. El desasosiego que esta situación produjo en Cesario de Arlés, puede comprobarse en la carta que ésta envió a Radegunda, MGH, Epp. aevi merov. et karol. I, 452.

19. Esta lista aparece en Düsseldorf, MS B4, fol. 11v. Tiene letra del siglo X y probablemente fue compuesta por la monja encargada de la biblioteca.

20. Universidad de Coimbra, Archivo, doc 1.

21. Hay que tener presente que copiar un manuscrito suponía una onerosa inversión.

22. Fulda, codex bonifatianus 2. 
23. Autun, 2. CLA VI, 716. Evangelia cum "expositionibus".

24. Cambrai 300, CLA VI, 739.

25. Paris, BN lat. 10865.

26. O al menos a evitar el olvido. No fue esta una época especialmente creativa, sino más bien un tiempo para conservar lo anterior.

27. Aún así, existe constancia de que esto sucedió a veces, por ejemplo en el de la vida de Gertrudis de Nivelles, escrita por un sacerdote, o el de la primera vida de Radegunda, compuesta por Venancio Fortunato. Y aún podrían citarse más casos. Sin embargo, en muchos de ellos consta que la obra se escribió por encargo y a partir de material aportado por las propias monjas.

28. Puede ser interesante para esta cuestión van der Esse, 1907.

29. No están incluidos en esta lista los autores y obras que han sido editados en las colecciones reseñadas en el apartado de abreviaturas empleadas. 


\section{REFERENCIAS BIBLIOGRÁFICAS}

Asser, J. Ælfredi regis res gestae. Keynes, S.; Lapidge, M. (trad.) (1983). Alfred the Great. Asser's Life of King Alfred and other Contemporary Sources. Harmondsworth: Penguin.

Beda. Historia ecclesiastica gentis anglorum. Colgrave, B.; Mynors, R.A.B. (eds.) (1991). Oxford: University Press. Sherley-Price, L. (trad) (1955). Harmondsworth: Penguin.

Bessmertny, Y. (1987). Le monde vu par une femme noble au Ixe siècle: la perception du monde dans l'aristocratie carolingienne. Le Moyen Âge, 93, 161-184.

Bischoff, B. (1931). Wer is die Nonne von Heidenheim?. Studien und Mitteilungen zur Geschichte des Benediktinerordens, 49, 387-97.

Bonifacio. Epistolae. Tangl, M. (ed.) (1955). MGH Epp. Selecti I Bonifacii et Lulli Epistolae, $2^{\text {nd }}$ ed., Berlin. Emerton, E. (trad.) (1940). The Letters of Saint Boniface New York: Columbia University Press. Talbot, C.H. (trad.). (1954). The Anglo-Saxon Missionaries in Germany, New York: Sheed and Ward, 63-149.

Braulio de Zaragoza. Epistolario. Riesco Terrero, L. (ed. y trad.). (1975). Epistolario de San Braulio de Zaragoza. Sevilla: Editorial Católica Española.

Cesario de Arlés, Regula ad Virgines, PL 67, 1103-1121. McCarthy, M.C. (trad.). (1960). The Rule for Nuns of St Caesarius of Arles: a translation with critical introduction. Washington: The Catholic University of America.

Contreni, J. J. (1990). The Tenth Century: The Perspective from the Schools, en Sot, M. (ed.) Haut Moyen-Age: Culture, éducation, et société, études offertes à Pierre Riché. Paris: Editions de l'E- space Européen, 379-387. Reed. en Contreni, J.J. (1992). Carolingian Learning: Masters and Manuscripts, Aldershot: Variorum, XII.

Delumeau, J. (ed.) (1992). La religion de ma mère. Le rôle des femmes dans la transmission de la foi. Paris: Les Éditions du Cerf.

Díaz y Díaz, M.C. (1979). Libros y librerías en la Rioja altomedieval. Logroño: Instituto de Estudios Riojanos.

Dhuoda, Liber Manualis. Riché, P. (ed.); Vregille, B. de; Mondésert, C. (trad.). (1975). Manuel pour mon fils, Paris: Cerf. Thiébaux, M. (trad.) (1998). Handbook for her warrior son. Cambridge: University Press. Neel, C. (trad.) (1999). Handbook for William: A Carolingian Woman's Counsel for her son. Lincoln: University of Nebraska Press. Merino, M. (trad.). (1995). La educación cristiana de mi hijo. Pamplona: Ediciones Eunate. (trad.). (1984) Educare nel medievo: Per la formazione di mio figlio: Manuale. Milano; Jaca Book.

Dronke, P. (1984). Women Writers of the Middle Age: A Critical Study of Texts from Perpetua (d. 203) to Marguerite Porete (d. 1310). Cambridge: University Press.

Egeria, Itinerarium (o Peregrinaito) Aetheriae. Prinz, O. (ed.) (1960). München: C. Winter. Pierre Maraval, V.; Díaz y Díaz, M. C. (eds. y trad.). (1982). París: Editions du Cerf.

Esse, L. van der (1907). Étude critique et littéraire sur les Vitae des saints mérovingiennes de l'ancien Belgique. Louvain-Paris: Kessinger Publishing.

Faust, U. (1984). Die Frauenklöster in Niedersachsen. Schleswig-Holstein und Bremen. St Ottilian: EOS. 
Gerberding, R. (1987). The Rise of the Carolingians and the Liber Historiae Francorum. Oxford: Clarendon Press.

Goffard, (1988). The Narrators of Barbarian History: Jordanes, Bede, Gregory of Tours and Paul the Deacon. Princeton: Princeton University Press.

Harrington, C. (2002). Women in a Celtic Church. Ireland 450-1150. Oxford: University Press.

Haselbach, I. (1970). Aufstieg und Herrschaft der Karolinger in der Darstellung der sogennanten Annales Mettenses Priores. Lübeck-Hamburg: Matthiesen.

Hlawitschka, E.; Schmid, K.; Tellenbach, G. (eds.). (1981). Liber Memorialis von Remiremont. MGH, Mem. I, München.

Hoffmann, H. (1958). Untersuchungen zur karolingischen Annalistik. Bonn: L. Röhrscheid.

Holzmann, R. (1961). Geschichte der sächsischen Kaiserzeit, 900-1024. Munich: Deutscher Taschenbuch Verlag.

Karpp, G. (1988). Bemerkungen zum Bücherbesitz des Essener Damenstifts um 900, en Honscheid, J.; Karpp, G. (eds.) Octogenario. Dankgabe für Heinrich Karpp überreicht von Schülern, Verwandten und Bekannten. Düsseldorf: Selbstverlag, 51-115.

Jong, M. B. de (1986). Kind en klooster in de vroege middeleeuwen: aspeckten van de schenking van kinderen aan kloosters in het Frankische Rijk (500-900). Amsterdam: Diessertatie Universiteit van Amsterdam.

Laistner, M. L. W. (1957). Thought and Letters in Western Europe AD 500-900. $2^{\text {nd }}$ ed. rev. Ithaca: Cornell University Press.

Lapidge, M. (1992). Artistic and Literary Patronage in Anglo-Saxon England, en Committenti e produzione artistico-let- teraria nell'alto medioevo occidentale. Spoletto: Centro di Studi sull Alto Medioevo, 137-91. Reed. Lapidge, M. (1996) Anglo-Latin Literature 600-899, London \& Rio Grande: Hambledon Press, 37-91.

Lapidge, M. (1996). Latin Learning in Ninth-Century England, en Lapidge, $M$. Anglo-Latin Literature 600-899. London-Rio Grande: Hambledon Press, 409-454.

Lett, D. (1999). The Child in Christendom, Fifth-Thirteenth Centuries, en Alexandre-Bidon, D.; Lett, D. Children in the Middle Ages. Fith-Fifteenth Centuries. Notre Dame, Indiana: University of Notre Dame Press, 7-74.

Lohier, F.; Laorte, R.P.J. (eds.) (1936). Gesta Sanctorum Patrum Fontanellensis coenobii- Gesta Abbatum Fontanellensium. Rouen-Paris: A. Lestringant.

Mattoso, J. (1981). As familias condais portucalenses dos séculos X e XI, en Mattoso, J. A Nobreza medieval portuguesa. Lisboa: Estampa, 101-57.

McKitterick, R. (1983). The Frankish Kingdoms under the Carolingians, 751-987, New York-London: Longman.

McKitterick, R. (1986-90). Anglo-Saxon Missionaries in Germany: Reflections on the Manuscript Evidence. Transactions of the Cambridge Bibliographical Society. 9, 291-329. Repr. en McKitterick, R. (1994). Books, Scribes and Learning in the Merovingian Kingdoms, $6^{\text {th }}-9^{\text {th }}$ Centuries. Aldershot: Variorum, IV.

McKitterick, R. (1989a). The Carolingians and the Written Word. Cambridge: University Press.

McKitterick, R. (1989b). The diffusion of Insular culture in Neustria between 650 and 850: the implications of the manuscript evidence, en Atsma, $\mathrm{H}$. (ed.) La Neustrie. Les pays au nord de la 
Loire de 650 à 850. Sigmaringen: Thorbecke, 392-435.

McKitterick, R. (1991). Frauen und Schriftlichkeit in Frühmittelalter, en Goetz H.W. (ed.) Weibliche Lebensgestaltung im frühen Mittelalter. KölnWien: Bühlau, 65-118.

McKitterick, R. (1994a). Script and Book Production, en McKitterick, R. (ed.) Carolingian Culture: emulation and innovation. Cambridge: University Press, 221-247.

McKitterick, R. (1994b). Women and literacy in the early middle ages, en McKitterick, R. Books, Scribes and Learning in the Merovingian Kingdoms, $6^{\text {th }} 9^{\text {th }}$ Centuries. Aldershot: Variorum, XIII.

Merino, M. (ed.) (1995). Dhuoda, La educación cristiana de mi hijo, Introducción, traducción y notas. Pamplona: Ediciones Eunate.

Mütherich, F.; Gaehde, J. (1976). Carolingian Painting, London-New York: George Braziller.

Neel, C. (1999). Handbook for William: A Carolingian Woman's Counsel for her son, Medieval texts in Translation. Lincoln: University of Nebrasca Press.

Nelson, J. L. (1990a). Literacy in Carolingian government, en McKitterick, R. (ed.) The Uses of Literacy in Early Mediaeval Europe. Cambridge: University Press, 258-296.

Nelson, J. L. (1990b). Perceptions du pouvoir chez les historiennes du haut moyen âge, en Rouche, M. (ed.) Les femmes au moyen âge. Paris: Touzot, 77-85.

Nelson, J. L. (1996a). Gender and Genre in Women Historians of the Early Middle Ages, en Nelson, J. L. The Frankish World 750-900. London-Rio Grande: Hambledon, 183-197.
Nelson, J. L. (1996b). Women and the Word in the Early Middle Ages, en Nelson, J. L. The Frankish World 750-900. London-Rio Grande: Hambledon, 200221.

Orme, N. (2002). Education in the West of England 1066-1548. Exeter: University of Exeter Press.

Orme, N. (2006). Medieval Schools. From Roman Britain to Renaissance England. Yale: University Press.

Parkes, M. B. (1983). A Fragment of an Early Tenth-Century Anglo-Saxon Manuscript and its Significance. Anglo-Saxon England, 12, 120-140.

Riché, P. (1963). Les bibliothèques de trois aristocrates laïques carolingiens. Le Moyen Age, 69, 87-104.

Riché, P. (1975). (ed.) Dhuoda, Manuel pour mon fils. Paris : Cerf. Introducción, texto crítico y notas por Pierre Riché; traducción al francés por Bernard de Vregille y Claude Mondésert.

Riché, P. (1976) Education and Culture in the Barbarian West: Sixth Through Eighth Centuries. Columbia: Univ. of South Carolina Press.

Searle, E. (1984). Fact and Pattern in heroic History: Dudo of Saint-Quentin. Viator, 15, 119-137.

Sims-Williams, P. (1976). Cuthswith, seventh-century abbess of Inkberrow, near Worcester, and the Würzburg manuscript of Jerome on Ecclesiastes. Anglo-Saxon England, 5, 1-22.

Sonnleitner, K. (1987). Selbstbewusstsein und Selbstverständnis der ottonischen Frauen im Spiegel der Historiographie des 10. Jahrhunderts, en Hartel, R. (ed.) Geschichte und ihre Quellen. Festschrift für Friedich Hausmann zum 70. Geburstag. Graz: Akademische Drucku. Verlagsanstalt, 111-119. 
Sonnleitner, K. (1988). Die Annalistik der Ottonenziet als Quelle für die Frauengeschichte. Graz: Schrieftenreihe des Instituts für Geschichte.

Spilling, H. (1978). Angelsächsische Schrift in Fulda, en Brall, A. (ed.) Von der Klosterbibliothek zur Landesbibliothek. Fulda: Anton Hiersemann, 47-98.

Stafford, P. (1997). Queen Emma and Queen Edith. Oxford: Blackwell.

Stokes, W. (1890). Lives of the Saints from the Book of Lismore. London: Clarendon Press.

Talbot, C. H. (1954, 1981). The AngloSaxon Missionaries in Germany. New York: Sheed and Ward.
Villa, C. (1984). La "Lectura Terentii" I. Dal Ildemaro a Francesco Petrarca. Padua: Antenore.

Ward, E. (1990). Caesar's Wife: The Career of the Empress Judith 819-829, en Goodman, P.; Collins, R. (eds.) Charlemagne's Heir. New Perspectives on the Reign of Louis the Pious (814-40). Oxford: Clarendon Press, 205-227.

Wemple, S. F. (1981). Women in Frankish Society. Marriage and the Cloister, 500 to 900. Pennsylvania: University Press.

West, A.F. (1892, 2004). Alcuin and the Rise of the Christian Schools. Princeton: Heinemann, Honolulu: University of Hawaii Press. 


\section{ABREVIATURAS}

AA SS Acta Sanctorum. Bruxelles: Societé des Bollandistes, 1643-1940 (con varias reediciones posteriores).

Carm. Carmen / Carmina.

CCCM Corpus Christianorum Continuatio Medievalis, Turnhout: Brepols, 1966.

CIL Corpus Inscriptionum Latinarum, Berlin: Brandenburgische Akademie der Wissenschaften, 1893-2003 (20 vols.).

CLA LOWE, E. A. Codices Latini Antiquiores. A Palaeographical Guide to latin Manuscripts Prior to the Ninth Century, Oxford: Clarendon Press, 1934-1971, 11 vols. + Supp. por B. Bischoff.

HE BEDA EL VENERABLE, Historia Ecclesiastica.

MGH Monumenta Germaniae Historica

AA Scriptores, Auctores Antiquissimi

Con Leges, Concilia

Ep Epistolae

Fontes Fontes iuris Germanici antiqui

Formulae Formulae Merowingici et Karolini aevi

Mem Libri memoriales

SRG Scriptores rerum Germanicarum

SRM Scriptores rerum Merovingicarum

SS Scriptores

MS Manuscrito

PL MIGNE, J. P. Patrologia Latina, 1844-1855, 217 vols.

\section{PALABRAS CLAVE}

Alta Edad Media, Mujeres, Manuscritos, Scriptoria, Escuela, Educación.

\section{KEYWORDS}

Early Middle Age, Women, Manuscripts, Scriptoria, School, Education. 


\section{PERFIL ACADÉMICO DE LA AUTORA}

Ana Belén Sánchez Prieto, doctora en Historia Medieval, profesora del departamento de Ciencias y Técnicas Historiográficas en la Facultad de Ciencias de la Documentación en la Universidad Complutense de Madrid. Es miembro de los grupos de investigación "Bibliopegia", de la Universidad Complutense, y Platform for Medieval Literacy, de la Universidad de Utrecht, especializados respectivamente en la producción del libro antiguo y la alfabetización en la sociedad altomedieval.

Dirección de la autora: Universidad Complutense de Madrid Facultad de Ciencias de la Documentación Santísima Trinidad, 3 28010 Madrid E-mail: abs@ccdoc.ucm.es

Fecha de Recepción del artículo: 1. Febrero.2009

Fecha de Revisión del artículo: 30. Junio. 2009

Fecha de Aceptación del artículo: 26. Octubre. 2009 